\title{
Perceived parenting styles and emotional eating: The mediating role of coping styles
}

\author{
Fatma Nur $\mathrm{Ay}^{1}{ }^{\circledR}$, Zeynep Mackali ${ }^{\circledR}$ \\ 'Istanbul Arel University, Department of Psychology, Istanbul - Turkey \\ ${ }^{2}$ Istanbul Bilgi University, Department of Psychology, Istanbul - Turkey
}

\begin{abstract}
Objective: The aim of this study was to investigate the mediating role of avoidance and compensatory coping styles in the relationship between perceived parenting styles and emotional eating in adults.

Method: The study sample consisted of 301 individuals. The Young Parenting Inventory, the Emotional Eating Scale, the Young-Rygh Avoidance Inventory and the Young Compensatory Inventory were used to collect the study data.

Results: Age; body mass index; overcompensating coping style responses of rebellion and counterdependency; and distraction through activity seen in the avoidance coping style were significant predictors of emotional eating. However, the variable model created did not indicate that coping styles had a mediating effect on emotional eating behavior.

Conclusion: Consideration of early maladaptive schemas is valuable to understanding the psychological processes involved in emotional eating. The results of this study may be help to develop greater insight into emotional eating and guide emotional and behavioral interventions.
\end{abstract}

Keywords: Avoidance, coping style, emotional eating, overcompensation, perceived parenting

\section{INTRODUCTION}

Emotional eating is a form of binge eating behavior, performed in response to emotional needs rather than physiological needs. It can provide a temporarily satisfying and comforting psychological result in the presence of negative affect, similar to satiating a physical hunger. However, overeating as an effort to counter and soothe strong negative emotions or as a reward, can also provoke subsequent feelings of guilt and reinforce negative emotions and beliefs, and can become pathological and detrimental to health. Emotional eating is often associated with bulimia and binge-eating disorder (1,2). All 3 of these pathologies involve an impulsive effort to regulate emotions, usually negative feelings related to a poor self-concept, sadness, stress, and fear (3). Emotional eating behavior has been reported to be a potentially important determinant in the early diagnosis of eating disorders in nonclinical groups (4). Additional examination of the factors that influence emotional eating is still necessary to fully understand this complex behavior.

The current literature contains a limited number of studies that have analyzed the effects of an individual's early relationships with their parents on emotional eating. As a relatively recent field of research, the

How to cite this article: Ay FN, Mackali Z. Perceived parenting styles and emotional eating: The mediating role of coping styles. Dusunen Adam The Journal of Psychiatry and Neurological Sciences 2021;34:151-160.

Correspondence: Fatma Nur Ay, Istanbul Arel University, Department of Psychology, Istanbul - Turkey 
understanding and conceptualization of eating disorders continues to expand and be refined. The cognitive-behavioral approach to these disorders has been successful in some respects; however, it cannot fully explain or address the variables underlying emotional eating (5). Pugh (6) examined the use of schema models to supplement the cognitive-behavioral approach.

A schema is a representation of the surroundings and a means to process and respond to information. Waller et al. (5) proposed that negative basic beliefs about one's self, the immediate environment, and the world can develop as a result of early life experiences, continue to evolve with age, and can form the basis of behavioral patterns. Early maladaptive schemas (7) develop based on basic individual needs that are not met in childhood (8). Some studies have demonstrated an association between perceived parenting and eating pathologies $(9,10)$. Negative parenting experiences can have a significant impact on the development of eating disorders (5). Schema development and maintenance designed to cope with adverse early parenting experiences and negative emotions can include the development of avoidance techniques, such as dysfunctional eating behaviors (10). Emotional eating behavior as a means to ease the effects of negative emotions can be defined as a secondary avoidance strategy, that is, schema avoidance (11). Secondary avoidance is an effort to reduce the unwanted effects that occur due to the activation of a schema. Although binge eating is a common schema avoidance technique, induced vomiting and the use of laxatives may also be used to block schema activation (10). Schema avoidance can include not only evasion of thoughts and images that trigger the schema in cognitive terms, but also avoidance of situations, environments, and relationships that may activate the schema (7). For example, an anorectic individual may exhibit primary avoidance behavior using schema compensation processes to circumvent the trigger. The desperation and vulnerability created by possible negative emotions and experiences is sufficiently acute that the individual employs cognitive, emotional, and behavioral strategies to counter and not reinforce the existing schema (e.g., restricted eating, compulsive eating, compulsive exercise) (7). Secondary strategies are employed once the emotion has already been triggered. Schema compensation typically includes self-limiting behaviors. An individual with a restricted diet may exhibit perfectionist tendencies and set strict standards for themself in order to avoid the activation and unwanted effects of the current "failure" pattern (12). However, once techniques that were sufficient in childhood are no longer functional in adulthood, the individual's compensation process can become a vicious circle, leading to a confirmation of the schema. For example, the anxious efforts of an individual with an abandonment schema to preserve a relationship may, in fact, bring about its end, strengthening the core belief that they will always be left or abandoned (10). Research has indicated that eating pathologies may be associated with both primary and secondary avoidance, and that primary avoidance in the form of binge eating behavior and distraction through activity may be related $(12,13)$.

The literature suggests that overprotective parenting and rejection may be associated with pathological eating habits (14). Jones et al. (15) found that binge eating behavior was related to punitive parenting techniques and that a defectiveness and shame schema reflecting a belief of unworthiness may be a result. Waller and Calam (16) observed that impaired eating behaviors developed as a way to control the environment in response to overprotective, punitive, or otherwise adverse parenting styles. Examination of the relationships between pathological eating and coping styles has led to the observation that both binging and restrictive eating pathologies were avoidant behavior to counter the undesirable effects created by schemas (10). Simpson et al. (17) found that avoidance and self-calming coping were associated with eating disorders and served to protect against negative emotions. In addition, van Vreeswijk et al. (18) found a correlation between status-seeking, rebellion, egocentrism and intolerance to criticism and compensatory coping, and pointed out that emotional eating behavior is a safe way to counteract for a low tolerance of criticism that threatens individuality, status, and high standards. However, the research to date that examines the relationships between emotional eating and familial factors remains limited (19).

Perceived parenting that is warm and responsive appears to be associated with more functional coping styles (20), while parenting perceived as more authoritarian and oppressive may be associated with avoidance coping styles (21). Schema processes may serve to mediate the relationship between pathological eating and perceived adverse parenting (10). In a related study, it was noted that internalized critical and demanding parental modes could lead to thoughts that the individual should be punished, humiliating and 
shameful beliefs about their body, and provoke avoidance behavior when the effects were unbearable, including binge eating behavior as a way to self-soothe (22).

This study was designed to further explore this context. Since the schema model holds that early parenting experiences are important to the formation of negative beliefs and schema processes, and that these processes may mediate the relationship between parenting and impaired eating pathology (5), as well as the existing evidence that these variables may be related, the objective of this research was to examine the association between perceived parenting styles, emotional eating behavior, and avoidance and compensatory schema processes in adults. Specifically, the goal was to answer the following research questions:

1. Can emotional eating behavior in adult individuals be predicted by sociodemographic variables (gender, age, body mass index [BMI], marital status, educational status, presence of any psychiatric disorder in themselves or their parents, an important physical condition and changing home/school early in life, parental death, parental relationship status)?

2. Can emotional eating behavior in adult individuals be predicted by the perceived parenting styles of the individual's mother and father (controlling, dismissive/critical, emotional deprivation, exploitative/abusive, overprotective/neurotic, conditional/success-oriented, over-permissive/ indulgent, pessimistic/anxious, punitive, changeresistant/suppressed emotions), avoidance coping styles (psychosomatism, denial of distress, emotional control, social withdrawal, distraction through activity, numbness/suppressing emotions), and compensatory coping styles (status-seeking, rebellion, controlling, counterdependency, manipulation, egocentrism, intolerance to criticism)?

3. Can a structural model of a relationship between perceived parenting styles and avoidance and compensatory coping styles significantly predict emotional eating behavior?

Since emotional eating has been shown to be a determining factor for eating disorders in a nonclinical sample, the study model was tested in a nonclinical group (4).

\section{METHOD}

\section{Study Sample}

The study group consisted of 301 adult individuals: $67.8 \%$ $(n=204)$ female and 32.2\% ( $n=97)$ male. The participants volunteered to participate in response to an open invitation and represented different segments of the society. In all, 179 participants completed the questionnaires using a paper-pencil format and 122 used online questionnaires. The inclusion criteria were $\geq 18$ years of age and Turkish literacy. Candidates who had a diagnosis of any eating disorder or a cognitive problem that could prevent completion of the tests were excluded.

Of the study sample, $33.9 \%(\mathrm{n}=101)$ were married and $65.4 \%(\mathrm{n}=197)$ were single, $50.8 \%(\mathrm{n}=153)$ were aged $18-24$, and $61.1 \%(\mathrm{n}=184)$ were university graduates. BMI values calculated using information provided on a demographic information form indicated that $53.2 \%(n=160)$ of the participants were of normal weight. The mother of $91.4 \%(n=275)$ and the father of $86.4 \%(n=260)$ of the respondents were still alive and the parents of $83.4 \%(n=251)$ were living together. A current psychological disorder had been diagnosed in $5 \%(n=15)$ of the participants and in $7 \%(n=21)$ of their parents. A history of physiological disorder in childhood was reported in $7.3 \%(n=101)$, and $45.8 \%(n=138)$ of the sample stated that thy experienced a change in home/ school in childhood.

\section{Measures}

Demographic Information Form: Information about the participants' gender, age, marital status, body weight and height, educational status, presence of any psychiatric disorders diagnosed in themselves or their parents, a significant physical disorder or and changes in home/school status, and whether their parents were alive and living together was collected using a selfreport demographic information form.

Young Parenting Inventory (YPI): A validity and reliability study of a Turkish version of YPI (23) was conducted by Soygut et al. (24). The original 72-item scale with 17 subdimensions was reduced to a version with 64 statements and 10 factor structures. The respondent evaluates their perception of each parent's behavior during childhood using a 6-point Likert-type rating $(1=$ completely untrue, $6=$ describes the parent perfectly). A high score corresponds to the intensity of a perceived negative parenting style. The parenting characteristics associated with maladaptive schemas and beliefs are described as: controlling, dismissive/ critical, emotional deprivation, exploitative/abusive, overprotective/neurotic, conditional/success-oriented, over permissive/indulgent, pessimistic/fearful, punitive, and resistant to change/emotionally inhibited. The Cronbach's alpha internal consistency value of this study for the portion of the scale evaluating the mother ranged between 0.69 and 0.92 and from 0.62 to 0.93 for 
the father. The Cronbach's alpha value for the complete scale was 0.93 .

Young-Rygh Avoidance Inventory (YPAI): The YPAI (25) is a self-report scale developed to measure schema avoidance, which also reflects schema maintenance. The original version consists of 40 items and 14 subdimensions, and is scored using a 6-point Likert-type scale ( $1=$ completely untrue of me, $6=$ describes me perfectly). A high score indicates greater avoidance behavior. Reliability and validity analysis carried out by Soygut et al. (26) yielded a Turkish version consisting of 24 expressions and 6 dimensions: psychosomatism, intentionally not thinking about/denial of distressing subjects, emotional control and excessive rationality, social withdrawal, distraction through activity, and numbness/suppressing emotions. In this study, the Cronbach's alpha value for the scale was 0.71 , and the score for the subdimensions ranged from 0.37 to 0.73 .

Young Compensation Inventory (YCI): Young (27) developed the YCI to evaluate schema compensation, another means to preserve a schema. This self-report scale consists of 48 statements and 7 subdimensions, and uses a 6-point Likert-type scale ( $1=$ completely untrue of me, $6=$ describes me perfectly). A high score corresponds to greater compensatory behavior. The Turkish adaptation study of the scale was conducted by Karaosmanoglu et al. (28) and resulted in a structure of 35 items and 7 subdimensions: status-seeking, rebellion, control, counterdependency, manipulation, egocentrism, and intolerance of criticism. The Cronbach's alpha value obtained in this study for the Turkish adaptation of the scale was 0.91 and ranged from 0.62 to 0.85 . for the subdimensions.

Emotional Eating Scale (EES): Bilgen (29) conducted a validity and reliability study of the EES and created a Turkish tool to examine emotional eating behaviors that consists of 30 statements and 4 subdimensions to describe the source of the response: stress, negative emotions, defensiveness, and selfcontrol. The Cronbach's alpha internal consistency coefficient for the whole scale was determined to be 0.96 , and ranges from 0.63 to 0.94 for the subdimensions. In this study, the analysis of the whole scale determined a Cronbach's alpha value ranged from 0.95 , and the Cronbach alpha values for the sub-factors ranged between 0.61 and 0.92 .

\section{Procedure}

This study was approved by the Istanbul Arel University Ethics Committee. The data were collected between
December 2019 and February 2020. All of the participants provided informed consent before anonymously completing the demographic information form and the battery of 4 questionnaires, which took about 15 to 20 minutes.

\section{Statistical Analysis}

The study data were analyzed using IBM SPSS Statistics for Windows, Version 25.0 software (IBM Corp., Armonk, NY, USA) and the related Amos 24.0 structural equation modeling program. Since the Cronbach's alpha reliability values of the Turkish versions of the YPI, EES, YRAI, and YCI provide the assumption of normality, parametric tests were used to assess the data. Standard multiple regression analysis was conducted to test the predictability of the demographic characteristics (gender, age, marital status, parents' marital status, educational status, psychiatric disorder history of respondent or their parents, a significant physical disorder in childhood, changing home/school, whether the parents are alive and together, and BMI), perceived parenting styles, avoidance coping styles, and compensatory coping styles on emotional eating behavior. In order to include categorical demographic variables in the regression analysis, reference groups were created using artificial variables. Structural equation modelling was performed using the Amos 24 program to test the model for the mediating effect of avoidance and compensatory coping styles in the relationship between perceived parenting styles and emotional eating behavior.

\section{RESULTS}

\section{Regression Findings}

Standard multiple regression analysis was conducted to test the demographic information variables, perceived parenting styles of the mother and father, avoidance coping styles, and compensatory coping styles on emotional eating behavior. The results indicated that these variables significantly predicted emotional eating behavior $(\mathrm{F}[55-224]=4.164 ; \mathrm{p}<0.01)$ and explained $50.6 \%$ of the emotional eating behavior.

Significance tests of the regression coefficients demonstrated that the avoidance variable of distraction through activity $(\mathrm{t}=8.389 ; \mathrm{p}<0.019)$, and compensatory variables of rebelliousness $(t=2.194 ; \mathrm{p}<0.05)$ and counterdependency $(t=-1.978, p<0.05)$ were significant predictors of emotional eating. The age groups of 25-30 years $(\mathrm{t}=-2.472 ; \mathrm{p}<0.05)$ and $>40$ years $(\mathrm{t}=-3.505$; $\mathrm{p}<0.05)$ also significantly predicted emotional eating 
behavior. Finally, it was observed that the BMI categories of normal weight $(\mathrm{t}=2.595 ; \mathrm{p}<0.05)$, overweight $(t=3.958 ; \mathrm{p}<0.01)$, and obese $(\mathrm{t}=3.191 ; \mathrm{p}<0.05)$ were significant predictors of emotional eating. The standardized regression coefficients indicated that the relative order of importance of these variables was distraction through activity $(\beta=0.505)$, overweight status $(\beta=0.356)$, age $>40$ years $(\beta=-0.330)$, obese status $(\beta=0.239)$, normal weight $(\beta=0.222)$, rebelliousness $(\beta=0.155)$, age $25-30$ years $(\beta=-0.152)$, and counterdependency $(\beta=-0.127)$.

The results of the multiple regression analysis examining the effect of demographic variables, perceived styles of parenting, and avoidance and compensatory coping styles on emotional eating are presented in Table 1.

\section{Mediation Model Results}

Structural equation modeling was used to test the model created to assess the mediating role of coping styles in the relationship between perceived parenting styles and emotional eating behavior. This has been shown to be an effective statistical technique to test the association between observed and unobserved variables (30). Perceived parenting styles (controlling, dismissive/ critical, emotional deprivation, exploitative/abusive, overprotective/neurotic, conditional/success-oriented, over permissive/indulgent, pessimistic/fearful, punitive, and resistant to change/emotionally inhibited, each rated separately for mother and father), avoidance coping styles (psychosomatism, intentionally not thinking about/denial of distressing subjects, emotional control and excessive rationality, social withdrawal, distraction through activity, and numbness/suppressing emotions), compensatory coping styles (status-seeking, rebellion, control, counterdependency, manipulation, egocentrism and intolerance to criticism) and emotional eating (stress, negative emotions, defensiveness, and self-control) were tested with 4 latent variables and 37 observed variables in the structural equation model.

The standard Comparative Fit Index (CFI), the Normed Fit Index (NFI), and the Tucker-Lewis Index (TLI) goodness-of-fit values stated in the literature as $\geq 0.95$, chi-squared statistic $\left(\chi^{2} / \mathrm{SD}\right)$ ratio of $<3$, and a root mean square error of approximation (RMSEA) value of $\leq 0.08$ (30) were applied to the study model. The analysis showed that the study model did not demonstrate the expected fit $[2=3658.81, \mathrm{df}=624$, $\mathrm{CFI}=0.48, \mathrm{NFI}=0.44, \mathrm{TLI}=0.45, \mathrm{RMSEA}=0.12$; $\mathrm{p}<0.001]$. The theoretical model tested is presented in Figure 1 .

\section{DISCUSSION}

The results of this study demonstrated that the demographic variables of age and BMI were significant predictors of emotional eating behavior. The reference group for the age variable comprised individuals between the ages of 18-24 years, while the BMI reference group was composed of underweight individuals. Participants aged $>25-30$ and $>40$ exhibited less emotional eating behavior than those aged 18-24 years, depending on the direction of the correlation between emotional eating and age, which was the predictor variable. These findings suggest that the age variable was a negatively significant predictor of emotional eating. Konttinen et al. (31) also concluded that there was a negative and significant association between emotional eating behavior and age for the female participants of their study. Wingo et al. (32) found a decrease in the use of emotion-focused coping styles with progressing age. The emotional eating inclination may decrease with age and maturity. In addition, analysis of the association between emotional eating and BMI, the other determinant variable, revealed that normal weight, overweight, and obese individuals displayed greater levels of emotional eating behavior than the underweight participants; BMI was a positive and significant predictor of emotional eating behavior. While some studies in the literature have obtained similar results, there is also research with contrary findings. Masheb and Grilo (2) found no significant association between emotional binge eating and BMI. Geliebter and Aversa (33) concluded that the overweight group reported eating more than the other weight groups when experiencing negative emotions and situations, whereas underweight individuals reported eating more when experiencing positive emotions and situations. Nguyen-Rodriguez et al. (34) found no difference in emotional eating behavior in normal weight and overweight individual groups. Our findings substantiate those of Sevinçer and Konuk (35), who also noted that negative emotions often led to emotional eating in overweight individuals and a decrease in eating among underweight and normalweight individuals.

In our study, emotional eating was also significantly predicted by the avoidance mechanism of distraction through activity, and the compensating behaviors of rebelliousness, and counterdependency, which are considered schema maintainers. This finding is consistent with results previously reported about 
Table 1: Multiple regression analysis of emotional eating and demographic variables, perceived parenting styles, avoidance coping styles, and compensatory coping styles

\begin{tabular}{|c|c|c|c|c|c|}
\hline Variable & B & SD & $\boldsymbol{\beta}$ & $\mathbf{t}$ & $\mathbf{p}$ \\
\hline 1. Male & -0.123 & 0.108 & -0.075 & -1.143 & 0.254 \\
\hline 2. Age $25-30$ & -0.321 & 0.130 & -0.152 & -2.472 & $0.014^{*}$ \\
\hline 3. Age 31-35 & -0.134 & 0.191 & -0.049 & -0.698 & 0.486 \\
\hline 4. Age 36-40 & -0.350 & 0.203 & -0.116 & -10.728 & 0.085 \\
\hline 5. Age $>40$ & -0.659 & 0.188 & -0.330 & -30.505 & 0.001 \\
\hline 6. Single & 0.011 & 0.135 & 0.007 & 0.083 & 0.934 \\
\hline 7. High school education & -0.020 & 0.211 & -0.009 & -0.095 & 0.924 \\
\hline 8. University education & 0.053 & 0.201 & 0.034 & 0.263 & 0.793 \\
\hline 9. Master's degree & 0.191 & 0.219 & 0.087 & 0.872 & 0.384 \\
\hline 10. Doctorate degree & -0.007 & 0.298 & -0.002 & -0.023 & 0.982 \\
\hline 11. No psychological disorder & 0.300 & 0.188 & 0.085 & 10.594 & 0.112 \\
\hline 12. No parental psychological disorder & -0.011 & 0.169 & -0.004 & -0.064 & 0.949 \\
\hline 13. No physical discomfort in childhood & 0.030 & 0.159 & 0.010 & 0.187 & 0.852 \\
\hline 14. No home/school change & -0.047 & 0.080 & -0.031 & -0.587 & 0.558 \\
\hline 15. Mother's death & 0.096 & 0.167 & 0.035 & 0.573 & 0.567 \\
\hline 16. Father's death & 0.050 & 0.158 & 0.022 & 0.315 & 0.753 \\
\hline 17. Parent divorce & 0.046 & 0.164 & 0.017 & 0.279 & 0.781 \\
\hline 18. Parent separation & -0.176 & 0.227 & -0.042 & -0.774 & 0.440 \\
\hline 19. Normal weight & 0.342 & 0.132 & 0.222 & 2.595 & 0.010 \\
\hline 20. Overweight & 0.622 & 0.157 & 0.356 & 3.958 & 0.000 \\
\hline 21. Obese & 0.672 & 0.211 & 0.239 & 3.191 & 0.002 \\
\hline 22. Morbidly obese & 0.886 & 0.516 & 0.095 & 1.716 & 0.088 \\
\hline 23. Emotional deprivation-mother & -0.055 & 0.070 & -0.078 & -0.783 & 0.434 \\
\hline 24. Exploitative/abusive mother & 0.034 & 0.126 & 0.022 & 0.266 & 0.790 \\
\hline 25. Overprotective/neurotic mother & 0.067 & 0.070 & 0.086 & 0.946 & 0.345 \\
\hline 26. Conditional/success-oriented mother & 0.016 & 0.056 & 0.024 & 0.286 & 0.775 \\
\hline 27. Overpermissive/indulgent mother & 0.110 & 0.095 & 0.117 & 1.156 & 0.249 \\
\hline 28. Pessimistic/fearful mother & -0.008 & 0.043 & -0.014 & -0.176 & 0.860 \\
\hline 29. Punitive mother & 0.033 & 0.061 & 0.047 & 0.540 & 0.590 \\
\hline 30. Resistant to change/emotionally inhibited mother & 0.042 & 0.045 & 0.065 & 0.922 & 0.357 \\
\hline 31. Controlling mother & -0.052 & 0.083 & -0.073 & -0.624 & 0.533 \\
\hline 32. Dismissive/critical mother & 0.097 & 0.102 & 0.100 & 0.956 & 0.340 \\
\hline 33. Emotional deprivation- father & 0.048 & 0.068 & 0.081 & 0.710 & 0.479 \\
\hline 34. Exploitative/abusive father & -0.014 & 0.111 & -0.012 & -0.125 & 0.901 \\
\hline 35. Overprotective/neurotic father & -0.074 & 0.073 & -0.094 & -1.019 & 0.309 \\
\hline 36. Conditional/success-oriented father & -0.110 & 0.056 & -0.176 & -1.971 & $0.05^{*}$ \\
\hline 37. Overpermissive/indulgent father & -0.051 & 0.091 & -0.058 & -0.564 & 0.574 \\
\hline 38. Pessimistic/fearful father & 0.064 & 0.051 & 0.101 & 1.259 & 0.209 \\
\hline 39. Punitive father & 0.001 & 0.066 & 0.001 & 0.012 & 0.990 \\
\hline 40. Resistant to change/emotionally inhibited father & -0.017 & 0.041 & -0.029 & -0.416 & 0.678 \\
\hline 41. Controlling father & 0.116 & 0.081 & 0.173 & 10.432 & 0.153 \\
\hline 42. Dismissive/critical father & -0.090 & 0.095 & -0.107 & -0.948 & 0.344 \\
\hline 43. Psychosomatism & 0.058 & 0.051 & 0.072 & 1.123 & 0.263 \\
\hline
\end{tabular}


Table 1: Cont.

\begin{tabular}{|c|c|c|c|c|c|}
\hline Variable & B & SD & $\boldsymbol{\beta}$ & $\mathbf{t}$ & $\mathbf{p}$ \\
\hline 44. Numbness/suppressed emotions & -0.052 & 0.053 & -0.061 & -0.998 & 0.320 \\
\hline 45. Distraction through activities & 0.369 & 0.044 & 0.505 & 8.389 & 0.000 \\
\hline 46. Emotional control & -0.075 & 0.046 & -0.088 & -1.620 & 0.107 \\
\hline 47. Denial of distress & -0.014 & 0.044 & -0.019 & -0.328 & 0.743 \\
\hline 48. Withdrawal & -0.035 & 0.037 & -0.053 & -0.944 & 0.346 \\
\hline 49. Status seeking & -0.023 & 0.045 & -0.034 & -0.516 & 0.606 \\
\hline 50. Rebellion & 0.111 & 0.051 & 0.155 & 2.194 & 0.029 \\
\hline 51. Control & -0.026 & 0.058 & -0.031 & -0.443 & 0.658 \\
\hline 52. Counterdependency & -0.105 & 0.053 & -0.127 & -10.978 & 0.049 \\
\hline 53. Manipulation & -0.049 & 0.050 & -0.073 & -0.984 & 0.326 \\
\hline 54. Egocentrism & 0.014 & 0.038 & 0.024 & 0.354 & 0.724 \\
\hline 55. Intolerance of criticism & 0.038 & 0.060 & 0.047 & 0.634 & 0.526 \\
\hline$R=0.711, R^{2}=0.506, F_{(55-224)}=4.164, p<0.001$ & & & & & \\
\hline
\end{tabular}

SD: Standard deviation

pathological eating and schema processes $(12,13,17,18)$. Our findings were compatible with the new schema model for eating disorders described by Waller et al. (5).

There are very few studies examining the mediating role of schema processes in the association between perceived parenting styles and emotional eating behavior. Therefore, this study was designed to explore this area further to add to our existing knowledge and understanding. The theoretical model created did not demonstrate sufficient goodness of fit; the coping methods and perceived parenting styles did not reliably predict emotional eating. Additional influential variables noted according to the schema model for eating disorders include maladaptive schemas and schema modes $(5,6,8)$. Schema modes have been reported to play a mediating role in bingeeating behavior in the overweight/obese group (13). In addition, emotional eating behavior is associated with emotional awareness (36). These important variables may require further examination. Our research findings and those of the literature $(33,35)$ and the schema model (13) suggest that overweight and obese groups may be more at risk for emotional eating behavior. The fact that this study did not consist of only overweight and obese individuals may have impacted the significance of the model. It may be important to repeat the study with consideration of concepts such as early maladaptive schemas, schema modes, and emotion regulation in a larger sample of overweight and obese individuals. In addition, mixed design studies with qualitative interviews to examine people with different BMI levels may also prove valuable.

Emotional eating behavior is an eating problem that has not yet been included in the Diagnostic and Statistical Manual of Mental Disorders as a classification, but it is known to be significantly associated with eating disorders. Although studies on this subject are limited, the available research indicates that important points in the treatment of eating disorders are also important for emotional eating. Currently, awareness-based interventions have proven to be particularly effective for eating disorders (37). Therefore, psychoeducation or awareness-based psychosocial studies with people at risk of emotional eating may be warranted within the scope of protective-preventive mental health services. Knowledge about parental behaviors that may affect emotional eating may help individuals to develop alternative ways to cope with negative emotions and thoughts in a healthier way.

This study is one of only a few to collectively examine emotional eating, perceived parenting, and coping variables. However, it does have limitations. The study data were the responses of 301 adult participants over the age of 18; therefore, the generalizability of the findings from the sample is limited. A larger sample size in future studies may increase the power of the relationship between variables. In addition, the percentage of female participants in the sample was high, which restricts group comparison. The data collection tools are self-report instruments and include retrospective assessments (especially the YPI), and 


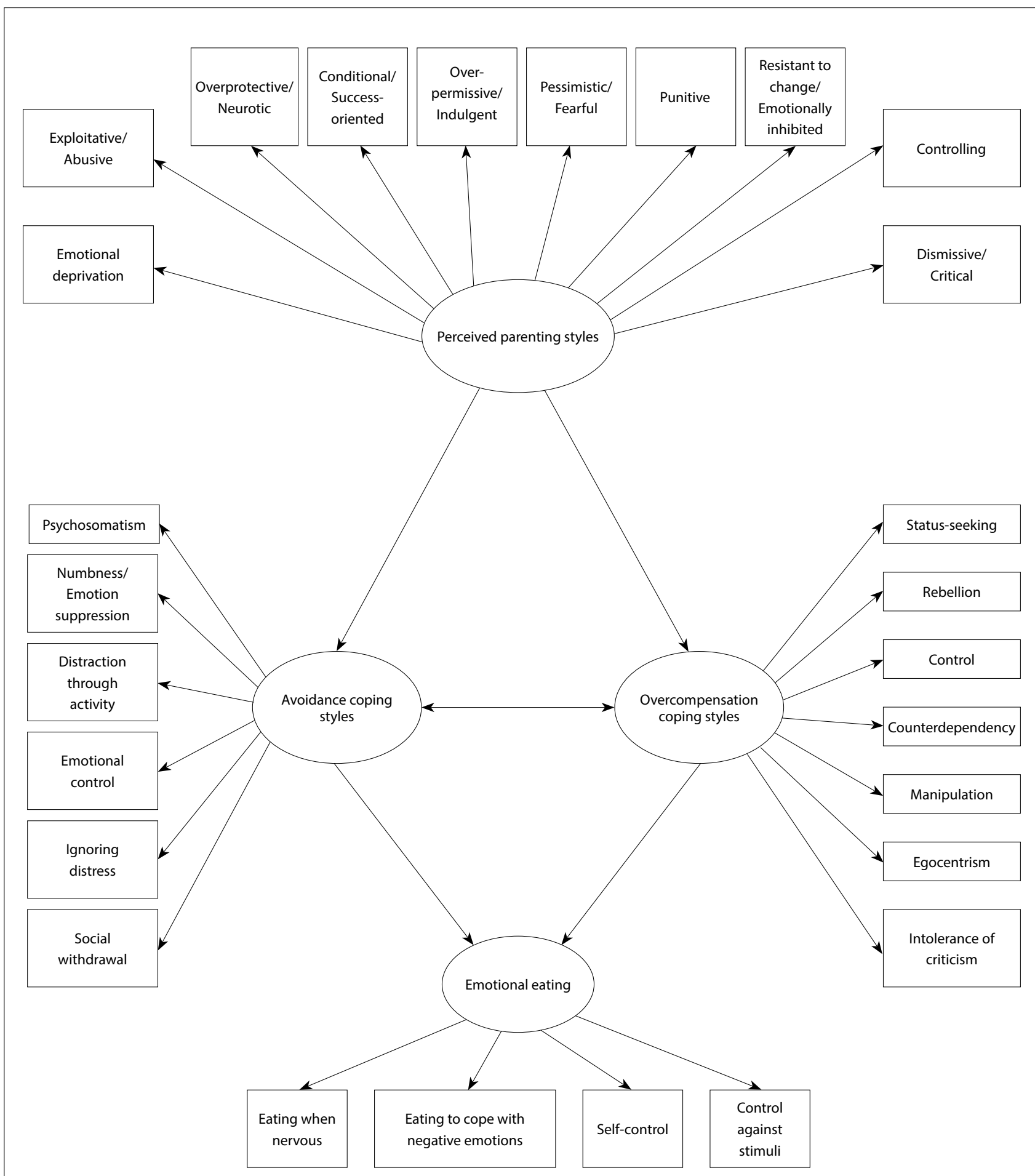

Figure 1. The hypothesis model tested.

individuals may have had difficulty answering or remembering some items, which could have had an unintended effect. Furthermore, the Turkish EEI is a newly developed scale. Although the validity and reliability level of this scale are sufficient, additional investigation of its use in various groups is advisable, and this also represents a limitation to the interpretation of this study.

A high level of emotional eating may be a behavioral reflection of avoidance and compensatory coping strategies developed to cope with the emotional effects of early experiences; however, further research is needed 
to fully comprehend the influences on emotional eating behavior.

\begin{tabular}{|c|c|c|}
\hline \multicolumn{2}{|c|}{ Contribution Categories } & \multirow{2}{*}{\begin{tabular}{|l} 
Author Initials \\
F.N.A., Z.M.
\end{tabular}} \\
\hline \multirow{3}{*}{ Category 1} & Concept/Design & \\
\hline & Data acquisition & F.N.A. \\
\hline & Data analysis/Interpretation & F.N.A. \\
\hline \multirow{2}{*}{ Category 2} & Drafting manuscript & F.N.A., Z.M. \\
\hline & Critical revision of manuscript & Z.M. \\
\hline Category 3 & Final approval and accountability & Z.M. \\
\hline \multirow{2}{*}{ Other } & Technical or material support & $\mathrm{N} / \mathrm{A}$ \\
\hline & Supervision & N/A \\
\hline
\end{tabular}

Ethics Committee Approval: This study was approved by the Istanbul Arel University Ethics Committee (no: 69396709-050.01.01).

Informed Consent: Written consent was obtained from the individuals participating in the study with an informed consent form.

Peer-review: Externally peer-reviewed.

Conflict of Interest: There is no conflict of interest between the authors.

Financial Disclosure: There is no financial support for the study.

\section{REFERENCES}

1. Abraham SF, Beumont PJ. How patients describe bulimia or binge eating. Psychol Med 1982; 12:625-635 Crossket

2. Masheb RM, Grilo CM. Emotional overeating and its associations with eating disorder psychopathology among overweight patients with binge eating disorder. Int J Eat Disord 2006; 39:141-146. CrossRef

3. Bekker MH, van de Meerendonk C, Mollerus J. Effects of negative mood induction and impulsivity on self-perceived emotional eating. Int J Eat Disord 2004; 36:461-469. [CrossRef]

4. Waller G, Osman S. Emotional eating and eating psychopathology among non-eating-disordered women. Int J Eat Disord 1998; 23:419-424. CrossRef]

5. Waller G, Kennerley H, Ohanian V. Schema-Focused CognitiveBehavioral Therapy for Eating Disorders. In Riso LP, du Toit PL, Stein DJ, Young JE editors. Cognitive Schemas and Core Beliefs in Psychological Problems: A Scientist-practitioner Guide. Washington: American Psychological Association, 2007, 139175. [CrossRef]

6. Pugh M. A narrative review of schemas and schema therapy outcomes in the eating disorders. Clin Psychol Rev 2015; 39:3041. [CrossRef]

7. Young JE, Klosko JS, Weishhar ME. Schema Therapy. Soylu TV (Translation Editor) Third ed., İstanbul: Litera Yayıncıllk, 2017.

8. da Luz FQ, Sainsbury A, Hay P, Roekenes JA, Swinbourne J, da Silva DC, da S Oliveira M. Early maladaptive schemas and cognitive distortions in adults with morbid obesity: relationships with mental health status. Behav Sci (Basel) 2017; 7:10. CrossRef
9. Turner HM, Rose KS, Cooper MJ. Parental bonding and eating disorder symptoms in adolescents: the meditating role of core beliefs. Eat Behav 2005; 6:113-118. [CrossRef]

10. Sheffield A, Waller G, Emanuelli F, Murray J, Meyer C. Do schema processes mediate links between parenting and eating pathology? Eur Eat Disord Rev 2009; 17:290-300. [CrossRef]

11. Heath G. An experimental test of a schema based model of eating disorders. Doctoral Dissertation, University of London; 2004.

12. Luck A, Waller G, Meyer C, Ussher M, Lacey H. The role of schema processes in the eating disorders. Cognit Ther Res 2005; 29:717-732. CrossRef]

13. Basile B, Tenore K, Mancini F. Early maladaptive schemas in overweight and obesity: A schema mode model. Heliyon 2019; 5:e02361. CrossRef]

14. Tata P, Fox J, Cooper J. An investigation into the influence of gender and parenting styles on excessive exercise and disordered eating. Eur Eat Disord Rev 2001; 9:194-206. CrossRef]

15. Jones C, Harris G, Leung N. Parental rearing behaviours and eating disorders: The moderating role of core beliefs. Eat Behav 2005; 6:355-364.

16. Pellizzer ML, Waller G, Wade TD. Predictors of outcome in cognitive behavioural therapy for eating disorders: An exploratory study. Behav Res Ther 2019; 116:61-68. [CrossRef]

17. Simpson S, Smith E, Brockman R, Tomkins A. An exploration of schema modes in clinical and sub-clinical eating disorders. International Society for Schema Therapy International Conference Presentation, Istanbul, 2011. https://www. researchgate.net/publication/267209002_An_exploration_ of_Schema_Modes_in_Clinical_and_Sub-Clinical_Eating_ Disorders. Accessed April 16, 2019.

18. van Vreeswijk M, Broersen J, Nadort M. The Wiley-Blackwell Handbook of Schema Therapy: Theory, Research, and Practice (Wiley Clinical Psychology Handbooks). First ed., Oxford: Wiley-Blackwell, 2012. [CrossRef]

19. Brown SL, Schiraldi GR, Wrobleski PP. Association of eating behaviors and obesity with psychosocial and familial influences. Am J Heal Educ 2009; 40:80-89. CCrossRet

20. Wolfradt U, Hempel S, Miles JNV. Perceived parenting styles, depersonalisation, anxiety and coping bahaviour in adolescents. Pers Individ Dif 2003; 34:521-532. [CrossRef]

21. Gong X, Fletcher KL, Bolin JH. Dimensions of perfectionism mediate the relationship between parenting styles and coping. J Couns Dev 2015; 93:259-268. [CrossRef]

22. Jamsen KM, Duffull SB, Tarning J, Lindegardh N, White NJ, Simpson JA. Optimal designs for population pharmacokinetic studies of the partner drugs co-administered with artemisinin derivatives in patients with uncomplicated falciparum malaria. Malar J 2012; 11:143 [CrossRef]

23. Young JE. Young Parenting Inventory (YPI) (On-line). NY: Cognitive Therapy Center, 1999, http://www.schematherapy. com/id205.htm. Accesed April 16, 2019.

24. Soygut G, Cakir Z, Karaosmanoglu A. Assessment of Parenting Styles: A Review of the Psychometric Properties of the Young Parenting Inventory. Turk Psikoloji Yazilari 2008; 11:17-30. 
25. Young, JE, Rygh J. Young-Rygh Avoidance Inventory (YRAI) (On-line). New York, NY: Cognitive Therapy Center, 1994. http://www.schematherapy.com. Accessed April 16, 2019.

26. Soygut G, Karaosmanoglu A, Cakir Z. Psychometric Properties of the Young Avoidance Inventory, 2007. http://www.hupal. hacettepe.edu.tr/dosyalar/diger/yrko_psikometrik.docx. Accesed April 16, 2019.

27. Young, JE. Young Compensatory Inventory (YCI) (On-line). New York, NY: Cognitive Therapy Center, 1995, http://www. schematherapy.com/id43.htm. Accessed April 16, 2019.

28. Karaosmanoğlu HA, Soygüt G, Kabul A. Psychometric properties of the Turkish Young Compensation Inventory. Clin Psychol Psychother 2013; 20:171-179. [CrossRef]

29. Bilgen SS. Validity and reliability study on the development of Turkish emotional eating inventory. Postgraduate Thesis, Uskudar University Institute of Social Sciences, Istanbul, 2018.

30. Meydan $\mathrm{CH}$, Sesen H. Structural equation modeling AMOS applications. Ankara: Detay Yayıncılık, 2011

31. Konttinen H, Männistö S, Sarlio-Lähteenkorva S, Silventoinen K, Haukkala A. Emotional eating, depressive symptoms and self- reported food consumption. A population-based study. Appetite 2010; 54:473-479. CrossRef]

32. Wingo AP, Baldessarini RJ, Windle M. Coping styles: longitudinal development from ages 17 to 33 and associations with psychiatric disorders. Psychiatry Res 2015; 225:299-304. CrossRef]

33. Geliebter A, Aversa A. Emotional eating in overweight, normal weight, and underweight individuals. Eat Behav 003; 3:341-347

34. Nguyen-Rodriguez ST, Chou CP, Unger JB, Spruijt-Metz D. $\mathrm{BMI}$ as a moderator of perceived stress and emotional eating in adolescents. Eat Behav 2008; 9:238-246 [CrossRef]

35. Sevincer GM, Konuk N. Emotional eating. J Mood Disord 2013; 3:171-178

36. Van Strien T, Engels RC, Van Leeuwe J, Snoek HM. The Stice model of overeating: tests in clinical and non-clinical samples. Appetite 2005; 45:205-213. [CrossRef]

37. Katterman SN, Kleinman BM, Hood MM, Nackers LM, Corsica JA. Mindfulness meditation as an intervention for binge eating, emotional eating, and weight loss: A systematic review. Eat Behav 2014; 15:197-204. 